\title{
Recuperação do nitrogênio das fontes sulfato e nitrato de amônio pelo milho em sistema semeadura direta
}

\author{
Anderson Lange ${ }^{(1)}$, Waldo Alejandro Ruben Lara Cabezas ${ }^{(2)}$ e Paulo César Ocheuze Trivelin ${ }^{(3)}$
}

\begin{abstract}
(1)Universidade do Estado de Mato Grosso, MT 208, Km 147, Jardim Tropical, CEP 78580-000 Alta Floresta, MT. E-mail: andersonlange@unemat.br (2)Agência Paulista de Tecnologia dos Agronegócios, Pólo Regional Nordeste Paulista, CEP 15500-970 Votuporanga, SP. E-mail: waldolar@aptaregional.sp.gov.br ${ }^{(3)}$ Centro de Energia Nuclear na Agricultura, Caixa Postal 96, CEP $13400-970$ Piracicaba, SP. E-mail: pcotrive@cena.usp.br
\end{abstract}

\begin{abstract}
Resumo - O objetivo deste trabalho foi avaliar a influência das épocas de parcelamento do nitrogênio suplementar à semeadura, nas concentrações foliares e na produtividade de grãos do milho, cultivado após dois anos de soja, e quantificar a recuperação do nitrogênio do fertilizante, pela técnica da diluição isotópica $\left({ }^{15} \mathrm{~N}\right)$. Os tratamentos constaram da aplicação de $70 \mathrm{~kg} \mathrm{ha}^{-1}$ de nitrogênio, como dose suplementar à adubação de semeadura do milho em épocas distintas: na semeadura da aveia-preta; oito dias antes da semeadura do milho; em cobertura, quando as plantas tinham quatro a cinco folhas; e em cobertura quando as plantas tinham sete a oito folhas. Não há diferença para as concentrações foliares e produtividade de grãos, quando se aplica nitrogênio suplementar à adubação de semeadura ou não, independentemente da época de aplicação, após o cultivo de soja por dois anos, em área de sistema semeadura direta. A recuperação do nitrogênio é superior no compartimento planta inteira, quando aplicado em cobertura, em relação à aplicação em pré-semeadura. O parcelamento do nitrogênio em cobertura não melhora a recuperação do fertilizante em relação a uma única aplicação.
\end{abstract}

Termos para indexação: Glycine max, Zea mays, épocas de aplicação, nitrogênio recuperado na planta, pré-semeadura.

\section{Recovery of nitrogen from ammonium sulfate and nitrate by corn crop in no-tillage system}

\begin{abstract}
The objective of this work was to evaluate the influence of different timing of nitrogen split application during corn crop seeding, on nutrient concentration of leaves and on corn yield, after two years of soybean cultivation; and to quantify the recovery of nitrogen fertilizer using the isotopic dilution technique $\left({ }^{15} \mathrm{~N}\right)$. Treatments consisted of $70 \mathrm{~kg} \mathrm{ha}^{-1}$ nitrogen application at corn crop seeding in distinct times: during seeding of oat, before corn seeding ( 8 days), at corn broadcasting (4-5 leaves), and at corn broadcasting (7-8 leaves). There is no difference for leaf nutrient concentrations and productivity of corn, after nitrogen supplementation at corn crop seeding, independently of application timing, after two years of soybean cultivation in no-tillage system. Nitrogen recovery is higher in the compartment plant, when applied in coverage, compared to the applied before corn seeding. The split application of nitrogen in coverage does not improve the recovery of fertilizer in a single application.
\end{abstract}

Index terms: Glycine max, Zea mays, application date, plant nitrogen recovery, pre-seeding.

\section{Introdução}

Entre as dificuldades encontradas pelos produtores que optaram pelo sistema semeadura direta (SSD), na Região do Cerrado, a produção de palha para cobrir o solo na entressafra e o manejo do nitrogênio $(\mathrm{N})$ têm se destacado, pois ambos são extremamente afetados pelas condições climáticas. A antecipação da cobertura nitrogenada, destinada à cultura do milho, aplicada na semeadura da planta de cobertura (Pauletti \& Costa, 2000) ou em pré-semeadura do milho (Sá, 1999; Basso \& Ceretta, 2000; Mai et al., 2003; Lara Cabezas et al., 2004, 2005; Pöttker \& Wiethölter, 2004) tem sido estudada, tendo por objetivo, na Região Sul do país, a redução na competição entre a cultura do milho e o solo (imobilização) pelo $\mathrm{N}$ aplicado no momento da semeadura. A similaridade entre aplicação de $\mathrm{N}$ em présemeadura e cobertura é destacada em alguns estudos 
(Pöttker \& Wiethölter, 2004; Lara Cabezas et al., 2005), porém, em anos de elevada pluviosidade, no período logo após a aplicação do $\mathrm{N}$ em pré-semeadura, verificou-se redução na produtividade do milho (Basso \& Ceretta, 2000). Em relação à aplicação do $\mathrm{N}$ em cobertura, o parcelamento pode resultar ou não em ganhos na produtividade (Sangoi \& Almeida, 1994; Escosteguy et al., 1997; Silva \& Silva, 2002).

A antecipação da aplicação de $\mathrm{N}$ vem sendo utilizada na região deste estudo, não com objetivo reduzir a carência de $\mathrm{N}$ no momento da semeadura do milho, já que normalmente a palha é escassa e a imobilização é menos crítica, e sim para otimizar o cronograma operacional da fazenda. Nessa situação, após a semeadura do milho, o maquinário fica disponível aos tratos culturais destinados à cultura da soja, que ocupa a maior percentagem das áreas.

Em vista do crescente cultivo de soja no país e da necessidade de se minimizar o custo de produção, beneficiar-se do $\mathrm{N}$ residual da soja pode propiciar economia de fertilizante, quando o milho é cultivado em sucessão (Gallo et al., 1983; Pereira et al., 1988; Sousa \& Lobato, 2004). Estudos relacionados a esse assunto foram desenvolvidos sob sistema de preparo convencional (SPC), e a literatura sobre o assunto é escassa, quando se trata de SSD. Assim, Araújo et al. (2004) estudaram o balanço do N no solo, após o cultivo da soja, e verificaram que pode haver aporte de $\mathrm{N}$ no sistema, em grande parte, graças ao $\mathrm{N}$ não recuperado do sistema radicular, em métodos tradicionais de amostragem, porém quantificado em estudos $\operatorname{com}{ }^{15} \mathrm{~N}$.

Trabalhos sobre o comportamento do N, na cultura do milho em SSD, foram realizados com uso do isótopo ${ }^{15} \mathrm{~N}$ (Lara Cabezas et al., 2004, 2005; Gava et al., 2006), porém há carência de informação em relação à aplicação em pré-semeadura e a um sistema que considere dois anos de soja como antecessora ao milho.

O objetivo deste trabalho foi avaliar a influência da época de aplicação do nitrogênio suplementar à adubação de semeadura, nas concentrações foliares de nitrogênio, cálcio, magnésio e enxofre e na produtividade de grãos do milho após dois anos de cultivo de soja, e quantificar a recuperação do nitrogênio, utilizando técnica isotópica $\left({ }^{15} \mathrm{~N}\right)$.

\section{Material e Métodos}

O trabalho foi desenvolvido entre abril de 2002 e abril de 2003, no Município de Uberlândia, MG, em um Latossolo Vermelho não-férrico, textura muito argilosa
( $710 \mathrm{~g} \mathrm{~kg}^{-1}$ de argila), situado a $19^{\circ} 4$ 'S e $48^{\circ} 7 \mathrm{~W}$, a $950 \mathrm{~m}$ de altitude, com histórico de oito anos sob SSD. A caracterização química do solo, antes da semeadura do milho, foi: $\mathrm{pH}_{\text {(água) }}, 5,2 ; \mathrm{P}_{\text {(Mehlich) }}, 14,4 \mathrm{mg} \mathrm{dm}^{-3} ; \mathrm{K}_{\text {(Mehlich) }}$, $92 \mathrm{mg} \mathrm{dm}^{-3}$; Ca, 1,1 $\mathrm{cmol}_{\mathrm{c}} \mathrm{dm}^{-3} ; \mathrm{Mg}, 0,3 \mathrm{cmol}_{\mathrm{c}} \mathrm{dm}^{-3}$; $\mathrm{Al}, 0,1 \mathrm{cmol}_{\mathrm{c}} \mathrm{dm}^{-3}$; CTC a pH 7, 6,4 $\mathrm{cmol}_{\mathrm{c}} \mathrm{dm}^{-3} ; \mathrm{V}, 26 \% \mathrm{e}$ MO, $33 \mathrm{~g} \mathrm{~kg}^{-1}$, para a camada de $0-20 \mathrm{~cm}$ de profundidade. No ano de 2001 foram aplicados superficialmente $1.100 \mathrm{~kg} \mathrm{ha}^{-1}$ de calcário.

Após a colheita da soja em 26/4/2002, semeou-se aveiapreta (Avena strigosa Schreb.), como planta de cobertura, em toda área experimental. Nessa ocasião, foram instalados cinco tratamentos com três repetições, em delineamento inteiramente casualizado, no total de 15 parcelas de $100 \times 4,8 \mathrm{~m}$ cada. O manejo adotado para a aplicação do $\mathrm{N}\left(70 \mathrm{~kg} \mathrm{ha}^{-1}\right)$, como dose suplementar à adubação de semeadura $\left(42 \mathrm{~kg} \mathrm{ha}^{-1}\right)$ na cultura do milho, foi: T1: 00-00-00-00; T2: 70-00-00-00; T3: 00-70-00-00; T4: 00-00-70-00; T5: 00-00-35-35, cuja sequência para cada tratamento corresponde à quantidade de $\mathrm{N}$ em quilogramas por hectare, aplicada da seguinte maneira: na semeadura da aveia-preta; oito dias antes da semeadura do milho; em cobertura, quando as plantas tinham quatro a cinco folhas; e em cobertura quando as plantas tinham sete a oito folhas. A aplicação do $\mathrm{N}$ suplementar à semeadura seguiu o seguinte procedimento: $\mathrm{T} 2$, incorporado abaixo e ao lado das sementes de aveia, com o auxílio de uma semeadora; T3, superficialmente, em faixas de $0,2 \mathrm{~m}$ de largura, distanciadas $0,8 \mathrm{~m}$ entre si (espaçamento de semeadura do milho); T4 e T5, superficialmente na entrelinha de semeadura do milho ( $0,3 \mathrm{~m}$ da linha), em faixas de $0,2 \mathrm{~m}$ de largura. Como fonte de $\mathrm{N}$ suplementar à semeadura, utilizou-se o formulado 18-0-24, composto de uma mistura de nitrato de amônio (NA) e sulfato de amônio (SA), 2:1 em produto comercial, na dose de $70 \mathrm{~kg} \mathrm{~N} \mathrm{ha}^{-1}$. $\mathrm{O}$ cloreto de potássio foi usado como fonte de $\mathrm{K}$.

Dois dias antes da semeadura do milho (4/11/2002), amostrou-se todo material vegetal que cobria o solo (cobertura morta e viva), para quantificar a cobertura. Um dia antes de semear o milho, realizou-se a dessecação das plantas espontâneas em todo o talhão do experimento (glifosato: $1.260 \mathrm{~g} \mathrm{ha}^{-1} \mathrm{em} 130 \mathrm{~L} \mathrm{ha}^{-1}$ de água). O milho - híbrido simples Fort (precoce) foi semeado em $6 / 11 / 02$, no espaçamento de $0,8 \mathrm{~m}$ entre linhas, para uma população de 60 mil plantas ha-1. A adubação de base do milho consistiu na aplicação de $350 \mathrm{~kg} \mathrm{ha}^{-1}$ da fórmula 12:24:6:2:10 (N:P:K:Ca:S), correspondente à mistura de sulfato de amônio, superfosfato simples, MAP e cloreto de potássio. 
A emergência das plantas ocorreu seis dias após a semeadura e, em 26/11, aplicou-se como pósemergente uma mistura dos herbicidas nicosulfuron (283 $\left.\mathrm{g} \mathrm{ha}^{-1}\right)$ e atrazine $\left(2.910 \mathrm{~g} \mathrm{ha}^{-1}\right) \mathrm{em} 150 \mathrm{~L} \mathrm{ha}^{-1} \mathrm{em}$ todo o experimento. A amostragem das folhas do milho foi realizada na primeira semana de janeiro de 2003 (florescimento), com a coleta das folhas abaixo e opostas à espiga, no total de 15 folhas por parcela, analisadas segundo Malavolta et al. (1997). Em 1\%/4/2003, avaliou-se a produtividade de grãos (umidade de $130 \mathrm{~g} \mathrm{~kg}^{-1}$ ), em $30 \mathrm{~m}$ lineares (três linhas de $10 \mathrm{~m}$ ). Em todas as amostragens, o material foi secado em estufa a $65^{\circ} \mathrm{C}$ até peso constante e foi, em seguida, moído finamente.

No momento da aplicação do fertilizante comercial interrompeu-se a operação para a introdução de microparcelas de $1,5 \mathrm{~m}$ e, nesse espaço, aplicou-se fertilizante enriquecido com ${ }^{15} \mathrm{~N}$, em três tratamentos: 00-70-00-00; 00-00-70-00; e 00-00-35-35. Em uma microparcela, aplicou-se a mistura de sulfato de amônio (SA- ${ }^{15} \mathrm{~N}$, concentração isotópica de $3,09 \pm 0,02 \%$ de átomos de ${ }^{15} \mathrm{~N}$ ) e nitrato de amônio (NA) com abundância natural de ${ }^{15} \mathrm{~N}$; em outra microparcela, aplicou-se SA com abundância natural de ${ }^{15} \mathrm{~N}$ e NA- ${ }^{15} \mathrm{~N}$ (concentração isotópica de 3,03 $\pm 0,01 \%$ de átomos de ${ }^{15} \mathrm{~N}$ ), obedecendo-se à dose, proporção entre fontes e modo de aplicação, como no resto do experimento. Apenas o amônio das fontes recebeu enriquecimento ( $43 \mathrm{~kg} \mathrm{ha}^{-1}$ de $\mathrm{N}$ na forma de amônio), e os resultados de recuperação percentual de $\mathrm{N}$ foram calculados com base nessa quantia. A aplicação ora com SA- ${ }^{15} \mathrm{~N}$, ora com NA- ${ }^{15} \mathrm{~N}$, denominada de técnica do espelho (Reddy \& Reddy, 1993), permite quantificar isoladamente o $\mathrm{N}$ aproveitado (recuperado) de cada fonte e em cada época (eficiência da fonte), já que a marcação nas duas fontes foi no $\mathrm{NH}_{4}{ }^{+}$. Para a determinação da eficiência de recuperação do nitrogênio $\left({ }^{15} \mathrm{~N}\right)$, colheram-se as plantas inteiras (acima do solo) de duas linhas paralelas à linha de aplicação do fertilizante. Os cálculos de recuperação foram:

a) percentagem de nitrogênio na planta, proveniente do fertilizante $(\% \mathrm{NPPF}): \% \mathrm{NPPF}=100\left(\%{ }^{15} \mathrm{~N}\right.$ amostra $-\%{ }^{15} \mathrm{~N}$ abundância natural) $/ \%{ }^{15} \mathrm{~N}$ fertilizante - \% ${ }^{15} \mathrm{~N}$ abundância natural), em que: $\%{ }^{15} \mathrm{~N}$ amostra é a abundância em percentagem de átomos de ${ }^{15} \mathrm{~N}$ na planta; $\%{ }^{15} \mathrm{~N}$ abundância natural é a abundância natural em percentagem de átomos de ${ }^{15} \mathrm{~N}$ na planta que não foi fertilizada; $\%{ }^{15} \mathrm{~N}$ fertilizante é a abundância em percentagem de átomos de ${ }^{15} \mathrm{~N}$ no fertilizante. b) nitrogênio total acumulado (NTA):

$\mathrm{NTA}=(\mathrm{N} \times \mathrm{MS}) / 1000$, em que NTAé o nitrogênio total acumulado, em kg ha ${ }^{-1} ; \mathrm{N}$ é a concentração de nitrogênio na amostra, em $\mathrm{g} \mathrm{kg}^{-1}$; MS é a massa de matéria seca da amostra, em kg ha-1.

c) quantidade de nitrogênio na planta proveniente do fertilizante (NPPF), em kg ha-1

$\mathrm{NPPF}=(\% \mathrm{NPPF} \times \mathrm{NTA}) / 100$, em que \%NPPF é a percentagem de $\mathrm{N}$ na planta proveniente do fertilizante. Nessa fase, os resultados são multiplicados pelo fator 2 . Esta correção deveu-se à forma de aplicação do N. Quando se aplica uma única faixa, na entrelinha, e colhem-se as duas linhas adjacentes à faixa de aplicação, admite-se que estas recuperam o fertilizante enriquecido (50\% do $\mathrm{N}$ recuperado pela planta), mas também recuperam $\mathrm{N}$ não enriquecido, proveniente do fertilizante adjacente, que não recebeu marcação. Ou seja, a planta recupera $\mathrm{N}$ do fertilizante aplicado em ambos os lados da linha, o qual deve ser computado nos cálculos.

d) eficiência de recuperação do fertilizante nitrogenado (\%ERFN):

$\mathrm{ERFN}=100(\mathrm{NPPF} / \mathrm{QNA})$, em que QNA é a quantidade de nitrogênio aplicado como fertilizante marcado, em quilograma por hectare; ERFN é a percentagem de $\mathrm{N}$ que foi aproveitado do total de fertilizante aplicado.

As análises de abundância de ${ }^{15} \mathrm{~N}$ do material enriquecido foram feitas em espectrômetro de massa automatizado, modelo ANCA-SL (Barrie \& Prosser, 1996).

Os resultados foram submetidos à análise de variância. As causas de variação significativas, relacionadas à cultura do milho, foram comparadas pelo teste $\mathrm{F}$ para contrastes ortogonais, a 5 e $10 \%$ de probabilidade, por meio do SAS.

\section{Resultados e Discussão}

As primeiras chuvas da estação ocorreram em setembro (45 mm) e em outubro $(88 \mathrm{~mm})$ na região, fato que deve ter estimulado a germinação de algumas espécies de plantas espontâneas, que aumentaram a quantidade de material vegetal sobre o solo no período de primavera. Antes da semeadura do milho (novembro de 2002), a superfície do solo apresentava cerca de $3,9 \mathrm{tha}^{-1}$ de massa de matéria seca (MMS), representada por uma diversidade de resíduos de soja, sorgo e plantas espontâneas que vegetavam, com destaque para o timbete (Cenchrus echinatus), e algumas braquiárias. 
A aplicação de N, complementar à adubação de semeadura, não alterou significativamente as concentrações foliares de $\mathrm{N}, \mathrm{Ca}, \mathrm{Mg}$ e $\mathrm{S}$ nem a produtividade de grãos do milho, em relação à ausência de aplicação (Tabela 1), resultado este que não se assemelha aos observados por Escosteguy et al. (1997) e Pöttker \& Wiethölter (2004), possivelmente, em razão das condições diferenciadas em que cada estudo foi desenvolvido, em que se destaca o sistema de rotação adotado neste trabalho. $\mathrm{O} N$ é um nutriente extremamente dinâmico no sistema solo-planta, as respostas à sua aplicação são diversificadas, em conseqüência de variações no clima, solo, sistema de rotação adotado e da época de aplicação (Basso \& Ceretta, 2000; Pauletti \& Costa, 2000; Mai et al., 2003).

As concentrações foliares de $\mathrm{N}$ e $\mathrm{S}$, cuja relação média foi de 15/1, estão na faixa considerada adequada, para a cultura do milho no Estado de Minas Gerais (Martinez et al., 1999), e de acordo com a literatura (Epstein \& Bloom, 2006). Para $\mathrm{Ca}$ e $\mathrm{Mg}$, as concentrações foliares estão abaixo do recomendado, provavelmente como resultado dos baixos teores desses nutrientes no solo, antes da semeadura do milho, que foram $1,1 \mathrm{e} 0,3 \mathrm{cmol}_{\mathrm{c}} \mathrm{dm}^{-3}$, respectivamente, na camada de $0-20 \mathrm{~cm}$. Entretanto, deve-se atentar para o fato de que as calibrações (padrões) dos nutrientes, no solo, e as foliares foram dimensionadas, em sua maioria, em experimentos sob SPC; no SSD, a dinâmica de nutrientes, a variabilidade horizontal e vertical são diferentes, pois causam a concentração dos nutrientes na superfície do solo, o que pode diferenciar a sua disponibilidade. Isto foi verificado em estudo de doses de $\mathrm{N}$, na região de Sete Lagoas, MG, em área de SSD, em que valores de saturação por bases (V\%) iguais a 33, na camada de $0-20 \mathrm{~cm}$, proporcionaram produtividade próxima a $10 \mathrm{tha}^{-1} \mathrm{de}$ grãos na cultura do milho (Lange et al., 2006a, 2006b). A maior concentração de nutrientes na camada superficial do solo, em SSD, provavelmente influenciou na nutrição da cultura, já que sintomas visuais de deficiência também não foram constatados; ademais, ressalta-se a existência de variabilidade genética de cada híbrido, o que pode influenciar este resultado.

A ausência de resposta à aplicação de $\mathrm{N}$ ocorreu em razão da fertilidade do solo, dos teores de matéria orgânica e, principalmente, do sistema de sucessão de culturas adotado na área, em que se cultivou a soja nas duas últimas safras. A depender do tempo de adoção do SSD e das condições locais, o caráter fonte de $\mathrm{N}$ da matéria orgânica do solo (MOS) pode predominar em relação ao caráter dreno (Sá, 1999; Mendonça \& Oliveira, 2000). O cultivo da soja pode resultar em balanço positivo de $\mathrm{N}$ ao sistema, principalmente no SSD (Araújo et al., 2004), em que pode haver aporte de $\mathrm{N}$ para a cultura subseqüente, decorrente do cultivo de soja (Sousa \& Lobato, 2004) e resultar, inclusive, em redução ou ausência de resposta à adubação nitrogenada aplicada no milho (Gallo et al., 1983; Pereira et al., 1988).

Os resultados para a aplicação de $\mathrm{N}$, apenas na semeadura, apresentaram coerência com a recomendação de $\mathrm{N}$ para cultura do milho no estados do Rio Grande do Sul e Santa Catarina, para áreas de plantio direto (Amado et al., 2002). Os autores recomendaram aplicar $50 \mathrm{~kg} \mathrm{ha}^{-1}$ de $\mathrm{N}$ na cultura do milho, para obtenção entre 6 e $9 \mathrm{t} \mathrm{ha}^{-1}$ de grãos, quando o solo apresentar entre 25 e $50 \mathrm{~g} \mathrm{~kg}^{-1}$ de $\mathrm{MO}$, e se tiver utilizado leguminosa de alta produção antes do milho. Neste trabalho, pode-se creditar à soja anteriormente cultivada, parte deste benefício.

Tabela 1. Contrastes para concentração foliar de nitrogênio $(\mathrm{N})$, cálcio $(\mathrm{Ca})$, magnésio $(\mathrm{Mg})$ e enxofre (S), e produtividade de grãos na cultura do milho em sucessão a dois anos de cultivo de soja, em sistema semeadura direta no Cerrado, em relação a diferentes épocas de parcelamento da adubação nitrogenada.

\begin{tabular}{|c|c|c|c|c|c|}
\hline Contraste $^{(1)}$ & $\mathrm{N}^{\mathrm{ns}}$ & $\mathrm{Ca}^{\mathrm{ns}}$ & $\mathrm{Mg}^{\mathrm{ns}}$ & $\mathrm{S}^{\mathrm{ns}}$ & $\begin{array}{c}\text { Produtividade } \\
\left(\mathrm{t} \mathrm{ha}^{\mathrm{ns}}\right)\end{array}$ \\
\hline 1.T1 vs T2, T3, T4, T5 & $31 \times 32$ & $2,2 \times 2,3$ & $1,5 \times 1,5$ & $2,1 \times 2,2$ & $8,21 \times 8,42$ \\
\hline 2.T2 vs T3, T4, T5 & $32 \times 32$ & $2,7 \times 2,2$ & $1,6 \times 1,5$ & $2,1 \times 2,2$ & $8,41 \times 8,42$ \\
\hline $3 . \mathrm{T} 3$ vs T4, T5 & $31 \times 32$ & $2,1 \times 2,3$ & $1,6 \times 1,5$ & $2,3 \times 2,1$ & $8,35 \times 8,46$ \\
\hline 4.T4 vs T5 & $34 \times 30$ & $2,2 \times 2,4$ & $1,5 \times 1,5$ & $2,1 \times 2,2$ & $8,43 \times 8,48$ \\
\hline Média & 32 & 2,3 & 1,5 & 2,1 & 8,38 \\
\hline $\mathrm{CV}(\%)$ & 8,7 & 17,4 & 3,8 & 18,5 & 8,4 \\
\hline Concentrações ${ }^{(2)}$ & $27,5-32,5$ & $2,5-4,0$ & $2,5-4,0$ & $1-2$ & - \\
\hline
\end{tabular}

(1) T1: 00-00-00-00; T2: 70-00-00-00; T3: 00-70-00-00; T4: 00-00-70-00; e T5: 00-00-35-35, cuja sequência em cada tratamento corresponde à quantidade de $\mathrm{N}$ em quilogramas por hectare, aplicada na semeadura da aveia-preta; oito dias antes da semeadura do milho; em cobertura quando as plantas estavam com quatro a cinco folhas; e em cobertura quando as plantas estavam com sete a oito folhas. (2) Concentrações de nutrientes na folha do milho, consideradas adequadas para o Estado de Minas Gerais (Martinez et al., 1999). nsNão-significativo. 
O clima favorável também contribuiu para os resultados de produtividade de grãos, pois não foram observados intervalos maiores que seis dias sem chuva (Figura 1), além das temperaturas favoráveis, em conformidade com as condições descritas por Fancelli \& Dourado Neto (2004).

Em relação à eficiência de recuperação do $\mathrm{N}$ (ERFN), das fontes sulfato de amônio (SA) e nitrato de amônio (NA) analisadas conjuntamente (43 $\left.\mathrm{kg} \mathrm{ha}^{-1} \mathrm{de}^{15} \mathrm{~N}\right)$, houve diferença significativa (Tabela 2) no compartimento palha (contrastes 3 e 4 ) e na planta inteira (contraste 5), em relação aos tratamentos testados. Quando o N foi aplicado todo em cobertura (T4 e T5), a recuperação foi maior na palha e na planta inteira, em relação à aplicação antes da semeadura (contrastes $3 \mathrm{e}$ 5). Lara Cabezas et al. (2004) também verificaram maior aproveitamento do $\mathrm{N}$, quando este foi aplicado em cobertura $(71 \%)$ em SSD, relativamente à aplicação em pré-semeadura (39\%). Possivelmente, parte do N aplicado em pré-semeadura, no tratamento T3 (oito dias antes da semeadura), pode ter sido imobilizada pelos resíduos da superfície do solo (3,9 t ha-1 de MMS com relação $\mathrm{C} / \mathrm{N}$ igual a 32). Apesar de as fertilizações terem sido aplicadas sobre a superfície do solo, em présemeadura, o potencial de imobilização poder ter sido maior, pois, após a aplicação do dessecante e da operação de semeadura, a decomposição do resíduo foi acelerada pelo maior contato deste com o solo, além da ocorrência de chuvas, que forneceram umidade ao sistema, o que evidenciou a dificuldade não só de formar palha na região, mas também de mantê-la no sistema.

Como observado em campo, no intervalo entre a aplicação em pré-semeadura e a primeira cobertura (29/10 a 28/11/2002), grande parte dos resíduos já havia sido decomposta, o que colaboraria para a menor imobilização do $\mathrm{N}$ aplicado em cobertura. Também, nesse período, a chuva acumulada foi de $170 \mathrm{~mm}$, o que pode ter provocado uma pequena lixiviação de $\mathrm{N}$ (Figura 1), porém de baixa magnitude, em conseqüência da textura do solo ( $710 \mathrm{~g} \mathrm{~kg}^{-1}$ de argila) e dos teores de

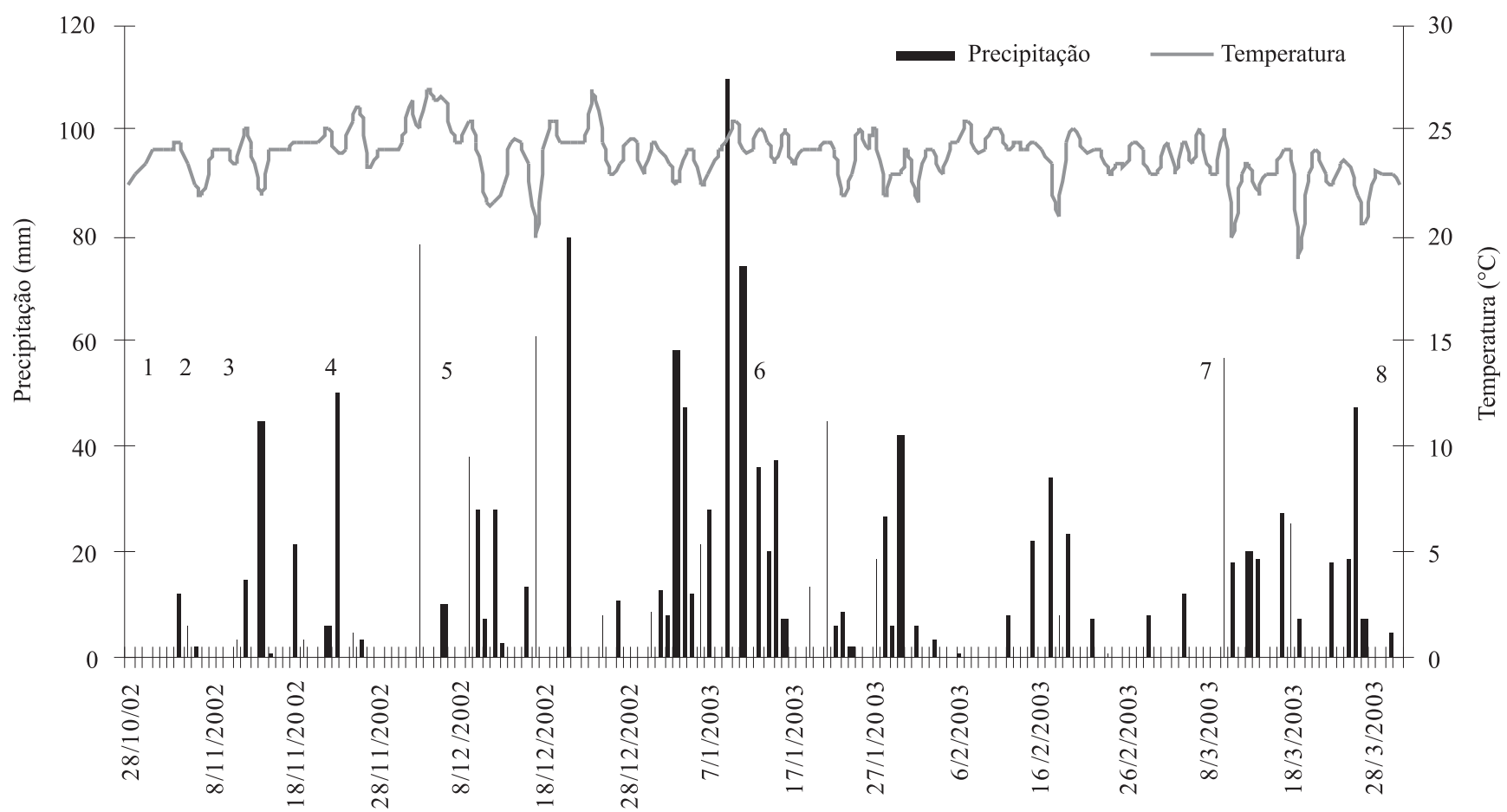

Figura 1. Temperatura média diária do ar e precipitação pluvial, durante o desenvolvimento do milho em sucessão a dois anos de cultivo de soja, na região do Cerrado. Precipitação mensal acumulada durante o ciclo da cultura: novembro (172 mm), dezembro (374 mm), janeiro (641 mm), fevereiro (114 mm) e março (291 mm). Legenda: 1, N em pré-semeadura (29/10/2002); 2, semeadura (6/11/2002); 3, emergência (12/11/2002); 4, N em cobertura quando as plantas estavam com quatro a cinco folhas (28/11/2002); 5, N em cobertura quando as plantas estavam com sete a oito folhas (9/12/2002); 6 , florescimento e análise foliar (10/1/2003); 7, ponto de maturidade fisiológica (8/3/2003); 8, colheita (1\%/4/2003). 
MO também adequados. Outro fator que pode promover o melhor aproveitamento do $\mathrm{N}$ de cobertura é a presença de sistema radicular na cultura, no momento da fertilização, condição diferente da aplicação em présemeadura. Em relação aos dois tratamentos, em que a aplicação foi feita em cobertura (T4 e T5), os resultados apontaram maior ERFN apenas na palha, quando se parcelou o $\mathrm{N}$ em duas épocas (contraste 4), porém, na planta inteira esse efeito não foi verificado. De modo geral, a ERFN, na planta inteira, da mistura NA e SA foi de $56 \%\left(24 \mathrm{~kg} \mathrm{ha}^{-1}\right)$, dos quais $16 \mathrm{~kg} \mathrm{ha}^{-1}$ exportados nos grãos e $8 \mathrm{~kg} \mathrm{ha}^{-1}$ remanescentes na palha, que retornaram ao sistema.

A cultura acumulou, em média, $185 \mathrm{~kg} \mathrm{ha}^{-1} \mathrm{de} \mathrm{N}$, dos quais $24 \mathrm{~kg} \mathrm{ha}^{-1}$ foram fornecidos pelo amônio das fontes NA e SA, aplicados como dose suplementar à adubação de semeadura (Tabela 2). Conforme documentado na literatura, em média, a recuperação do $\mathrm{N}$ na cultura do milho é de 50\% (Gava et al., 2006; Lara Cabezas et al., 2004, 2005). Admitindo-se que a cultura tenha recuperado esse mesmo percentual do $\mathrm{N}$ do nitrato, da fonte nitrato de amônio (13,5 $\left.\mathrm{kg} \mathrm{ha}^{-1}\right)$, que não recebeu marcação, e que $50 \%$ do $\mathrm{N}$ aplicado na semeadura também tenham sido recuperados $\left(21 \mathrm{~kg} \mathrm{ha}^{-1}\right)$, tem-se um total $59 \mathrm{~kg} \mathrm{ha}^{-1}$ de $\mathrm{N}(24+13,5+21)$ na planta inteira, provenientes do fertilizante aplicado na corrente safra, e o restante $\left(126 \mathrm{~kg} \mathrm{ha}^{-1}\right)$ originário de outras fontes (residual de culturas anteriores, decomposição de resíduos, fixação biológica, resíduos de fertilizações anteriores), o que mostra o potencial do solo em fornecer $\mathrm{N}$ para a cultura do milho.

Com um adequado manejo do solo, pode-se contar com até $180 \mathrm{~kg} \mathrm{ha}^{-1}$ de $\mathrm{N}$ provenientes da mineralização, e podem ser produzidos até $9 \mathrm{t} \mathrm{ha}^{-1}$ de grãos de milho (Sousa \& Lobato, 2004). Segundo os autores, para cada $1 \%$ de MOS, tem-se o fornecimento de $30 \mathrm{~kg} \mathrm{ha}^{-1} \mathrm{de}$ $\mathrm{N}$, o que equivaleria a $99 \mathrm{~kg} \mathrm{ha}^{-1} \mathrm{de} \mathrm{N}$, conforme o solo. De acordo com os mesmos autores, considerando-se as culturas das três safras antecessoras, tem-se: soja (58 sacos ha-1 x 0,22), sorgo (38 sacos ha-1 x 0,1) e soja (54 sacos ha-1 $\mathrm{x} 0,45$ ), que contribuíram com $41 \mathrm{~kg} \mathrm{ha}^{-1}$ de N. Assim totalizam-se aproximadamente $140 \mathrm{~kg} \mathrm{ha}^{-1}$ de $\mathrm{N}$, o que se aproxima da estimativa de $126 \mathrm{~kg} \mathrm{ha}^{-1} \mathrm{de}$ $\mathrm{N}$ supridos pelo solo neste trabalho.

Admitindo-se que o sistema radicular tenha acumulado entre 10 e $15 \mathrm{~kg} \mathrm{ha}^{-1}$ de $\mathrm{N}$, têm-se aproximadamente $200 \mathrm{~kg} \mathrm{ha}^{-1}$ de $\mathrm{N}$ na cultura. Estas estimativas confirmam a ausência de resposta em produtividade, em relação ao $\mathrm{N}$ aplicado como dose suplementar à adubação de semeadura. Apesar de a recuperação do $\mathrm{N}$ suplementar à adubação de semeadura chegar a $50 \%$, o solo pôde suprir aproximadamente $126 \mathrm{~kg} \mathrm{ha}^{-1} \mathrm{de} \mathrm{Ne}$, tendo-se aplicado $42 \mathrm{~kg} \mathrm{ha}^{-1}$ de $\mathrm{N}$ na semeadura (T1), estes valores se

Tabela 2. Contrastes calculados de nitrogênio (quilogramas por hectare) na planta proveniente do fertilizante (NPPF), e eficiência (\%) de recuperação do fertilizante nitrogenado (ERFN), na colheita do milho em sucessão a dois anos de cultivo de soja, em sistema semeadura direta no Cerrado, em relação a diferentes épocas de parcelamento da adubação nitrogenada ${ }^{(1)}$.

\begin{tabular}{|c|c|c|c|c|c|c|c|c|}
\hline \multirow[t]{2}{*}{ Contraste $^{(2)}$} & \multirow{2}{*}{$\begin{array}{l}\mathrm{N} \text { total }^{(3)} \\
\left(\mathrm{kg} \mathrm{ha}^{-1}\right)\end{array}$} & \multicolumn{2}{|c|}{ NA $\left(27 \mathrm{~kg} \mathrm{ha}^{-1}\right)$} & \multicolumn{2}{|c|}{$\mathrm{SA}\left(16 \mathrm{~kg} \mathrm{ha}^{-1}\right)$} & \multicolumn{2}{|c|}{$\mathrm{NA}+\mathrm{SA}\left(43 \mathrm{~kg} \mathrm{ha}^{-1}\right)$} & \multirow{2}{*}{$\begin{array}{l}\mathrm{NDOF}^{(3)} \\
\left(\mathrm{kg} \mathrm{ha}^{-1}\right)\end{array}$} \\
\hline & & $\begin{array}{c}\text { NPPF } \\
\left(\mathrm{kg} \mathrm{ha}^{-1}\right)\end{array}$ & $\begin{array}{c}\text { ERFN } \\
(\%)\end{array}$ & $\begin{array}{c}\text { NPPF } \\
\left(\mathrm{kg} \mathrm{ha}^{-1}\right)\end{array}$ & $\begin{array}{c}\text { ERFN } \\
(\%)\end{array}$ & $\begin{array}{c}\mathrm{NPPF} \\
\left(\mathrm{kg} \mathrm{ha}^{-1}\right)\end{array}$ & $\begin{array}{c}\text { ERFN } \\
(\%)\end{array}$ & \\
\hline & \multicolumn{8}{|c|}{ Grãos } \\
\hline $1 . \mathrm{T} 3 \times \mathrm{T} 4, \mathrm{~T} 5$ & $124 \times 122$ & $9 \times 12$ & $32 \times 44$ & $5 \times 5$ & $29 \times 31$ & $13 \times 17$ & $31 \times 39$ & $111 \times 105$ \\
\hline $2 . \mathrm{T} 4 \times \mathrm{T} 5$ & $118 \times 125$ & $12 \times 12$ & $45 \times 42$ & $4 \times 6$ & $27 \times 35$ & $16 \times 17$ & $38 \times 40$ & $102 \times 108$ \\
\hline Média & 122 & 11 & 40 & 5 & 31 & 15,9 & 37 & 106 \\
\hline \multirow[t]{2}{*}{$\mathrm{CV}(\%)$} & - & 33,8 & 33,8 & 29,0 & 29,0 & 20,5 & 20,5 & - \\
\hline & \multicolumn{8}{|c|}{ Palha } \\
\hline $3 . \mathrm{T} 3 \times \mathrm{T} 4, \mathrm{~T} 5$ & $63 \times 64$ & $3 \times 5$ & $13 \times 17$ & $3 \times 4$ & $17 \times 23$ & $6 \times 9 * *$ & $14 \times 20^{* *}$ & $57 \times 56$ \\
\hline $4 . \mathrm{T} 4 \times \mathrm{T} 5$ & $55 \times 72$ & $4 \times 5$ & $17 \times 18$ & $3 \times 5^{*}$ & $18 \times 29^{*}$ & $7 \times 10^{*}$ & $17 \times 22 *$ & $48 \times 63$ \\
\hline Média & 63 & 4,3 & 16 & 3,4 & 21 & 8 & 19 & 55 \\
\hline \multirow[t]{2}{*}{$\mathrm{CV}(\%)$} & - & 27,9 & 27,9 & 30,2 & 30,2 & 15,83 & 15,83 & - \\
\hline & \multicolumn{8}{|c|}{ Planta inteira } \\
\hline $5 . \mathrm{T} 3 \times \mathrm{T} 4, \mathrm{~T} 5$ & $187 \times 185$ & $12 \times 16$ & $45 \times 61$ & $8 \times 9$ & $47 \times 55$ & $20 \times 25^{*}$ & $45 \times 59^{*}$ & $167 \times 159$ \\
\hline $6 . \mathrm{T} 4 \times \mathrm{T} 5$ & $173 \times 196$ & $17 \times 16$ & $62 \times 61$ & $7 \times 10$ & $45 \times 64$ & $24 \times 27$ & $55 \times 62$ & $149 \times 169$ \\
\hline Média & 185 & 15,3 & 56,6 & 8,4 & 52 & 23,8 & 56 & 162 \\
\hline $\mathrm{CV}(\%)$ & - & 30,1 & 30,1 & 27,8 & 27,8 & 16,4 & 16,4 & - \\
\hline
\end{tabular}

${ }^{(1)} \mathrm{NA}$ : nitrato de amônio; SA: sulfato de amônio; $\mathrm{N}$ total: nitrogênio total acumulado; NDOF: nitrogênio derivado de outras fontes, além do ${ }^{15} \mathrm{~N}$ estudado (adubação de base, N não enriquecido, solo e outras fontes). ${ }^{(2)}$ T3: 00-70-00-00; T4: 00-00-70-00; e T5: 00-00-35-35, cuja seqüência, para cada tratamento, corresponde à quantidade de $\mathrm{N}$ em kg ha-1, aplicada oito dias antes da semeadura do milho; em cobertura quando as plantas estavam com quatro a cinco folhas; e em cobertura quando as plantas estavam com sete a oito folhas. ${ }^{(3)}$ Não foi realizada a análise estatística para $\mathrm{N}$ total e NDOF. $*$ e **Significativo a 10 e $5 \%$ de probabilidade, respectivamente. 
aproximam ao balanço de $\mathrm{N}$ para a cultura. Isto resultou em ausência de resposta em produtividade quando se compararam os tratamentos que receberam $\mathrm{N}$ suplementar e a testemunha.

$\mathrm{O} \mathrm{N}$ na planta inteira proveniente do NA aplicado variou entre 12 e $17 \mathrm{~kg} \mathrm{ha}^{-1}$ de $\mathrm{N}$ amoniacal, conforme a época, e foram recuperados, em média, $15 \mathrm{~kg} \mathrm{ha}^{-1}$ de N. Kitur et al. (1984) observaram ERFN média de 60\% no milho, em sistema de preparo convencional (SPC), e $37 \%$ em área de SSD, resultados decorrentes, possivelmente, de uma maior imobilização. Os resultados aqui observados, com recuperação média de $56 \%$, ocorreram, possivelmente, em razão da menor imobilização do N, em conseqüência do histórico da área com cultivo da soja por dois anos (solo com $\mathrm{N}$ residual), graças ao uso do SSD por oito anos e, também, porque em menores doses de $\mathrm{N}$, a recuperação do fertilizante tende a ser maior (Gava et al., 2006; Silva et al., 2006). A ERFN do SA aplicado antecipado ou em cobertura foi, também, semelhante nos grãos e na planta inteira. Entretanto, na palha residual, o parcelamento da cobertura em duas épocas (contraste 4) resultou em maior ERFN (29\%), em relação à aplicação em uma só época (Tabela 2). Em média, a ERFN do SA na planta inteira foi $52 \%$.

A ERFN total das duas fontes foi em média $54 \%$, dos quais $56 \%$ para o NA e $52 \%$ para o SA. Quanto à distribuição do $\mathrm{N}$, nas diferentes partes da planta, prevaleceu o acúmulo do $\mathrm{N}$ amoniacal proveniente do NA nos grãos, com média de $40 \%$ em relação à fonte $\mathrm{SA}$, que acumulou apenas $31 \%$ do $\mathrm{N}$ recuperado nesse compartimento. Na palha residual, observou-se comportamento contrário, com maior acúmulo de $\mathrm{N}$ amoniacal proveniente do SA (21\%), em relação ao NA $(16 \%)$.

\section{Conclusões}

1. A adubação nitrogenada suplementar à de semeadura, aplicada em diferentes épocas, ou a ausência de sua aplicação no milho, não altera a produtividade de grãos e as concentrações foliares de nitrogênio, cálcio, magnésio e enxofre, quando em sucessão a dois anos de cultivo de soja, em sistema semeadura direta, em condições de saturação por bases do solo abaixo da recomendada e expectativa de produtividade de até $8 \mathrm{tha}^{-1}$.

2. A recuperação do nitrogênio das fontes nitrato e sulfato de amônio pelo milho, na planta inteira, é superior quando o nitrogênio é aplicado em cobertura, em relação à aplicação em pré-semeadura; o parcelamento em cobertura não melhora a recuperação do fertilizante em relação a apenas uma aplicação.

3. Na palha residual, a recuperação do fertilizante nitrogenado suplementar à semeadura é superior, quando aplicado em cobertura, em relação à aplicação em présemeadura, assim como o parcelamento em cobertura melhora a sua recuperação.

\section{Agradecimentos}

À Fundação Agrisus - Agricultura Sustentável, ao SN - Centro de Pesquisa e Promoção de Sulfato de Amônio Ltda., e aos proprietários da Fazenda Floresta do Lobo - Pinusplan Reflorestadora Ltda., pelo apoio financeiro; ao Centro de Energia Nuclear na Agricultura, pela realização das análises isotópicas; ao Conselho Nacional de Desenvolvimento Científico e Tecnológico, por concessão de bolsa.

\section{Referências}

AMADO, T.J.C.; MIELCNIZUK, J.; AITA, C. Recomendação de adubação nitrogenada para o milho no RS e SC adaptada ao uso de culturas de cobertura do solo, sob sistema plantio direto. Revista Brasileira de Ciência do Solo, v.24, p.179-189, 2002.

ARAÚJO, E.S.; MEDEIROS, A.F.A.; DIAS, F.C.; URQUIAGA, S.; BODDEY, R.M.; ALVES, B.J.R. Quantificação do N do solo derivado das raízes da soja utilizando o isótopo ${ }^{15} \mathrm{~N}$. Revista Universidade Rural, v.24, p.7-12, 2004.

BARRIE, A.; PROSSER, S.J. Automated analysis of light-element stable isotopes by isotope ratio mass spectrometry. In: BOUTTON, T.W.; YAMASAKI, S. (Ed.). Mass spectrometry of soils. New York: Marcel Dekker, 1996. p.1-46.

BASSO, C.J.; CERETTA, C.A. Manejo do nitrogênio em sucessão a plantas de cobertura de solo, sob plantio direto. Revista Brasileira de Ciência do Solo, v.24, p.905-915, 2000.

EPSTEIN, E.; BLOOM, A.J. Nutrição mineral de plantas: princípios e perspectivas. Londrina: Editora Planta, 2006. 403p.

ESCOSTEGUY, P.A.V.; RIZZARDI, M.A.; ARGENTA, G. Doses e épocas de aplicação de nitrogênio em cobertura na cultura do milho em duas épocas de semeadura. Revista Brasileira de Ciência do Solo, v.21, p.71-77, 1997.

FANCELLI, A.L.; DOURADO NETO, D. Produção de milho. 2.ed. Guaíba: Agropecuária, 2004. v.1.360p.

GALLO, P.B.; SAWASAKI, E.; HIROCE, R.; MASCARENHAS, H.A.A. Produção de milho afetada pelo nitrogênio mineral e cultivos anteriores com soja. Revista Brasileira de Ciência do Solo, v.7, p.149-152, 1983. 
GAVA, G.J.C.; TRIVELIN, P.C.O.; OLIVEIRA, M.W.; HEINRICHS, R.; SILVA, M.A. Balanço do nitrogênio da uréia $\left({ }^{15} \mathrm{~N}\right)$ no sistema solo-planta na implantação da semeadura direta na cultura do milho. Bragantia, v.65, p.477-486, 2006.

KITUR, B.K.; SMITH, M.S.; BLEVINS, R.L.; FRYE, W.W. Fate of ${ }^{15} \mathrm{~N}$-depleted ammonium nitrate applied to no-tillage and conventional tillage corn. Agronomy Journal, v.76, p.240-242, 1984.

LANGE, A.; CARVALHO, J.L.; DAMIN, V.; CRUZ, J.C.; GUILHERME, L.R.G.; MARQUES, J.J. Doses de nitrogênio e de palha em sistema plantio direto de milho no Cerrado. Revista Ceres, v.53, p.171-178, 2006.

LANGE, A.; DAMIN, V.; CARVALHO, J.L.; CRUZ, J.C.; MARQUES, J.J. Alterações em atributos do solo decorrentes da aplicação de nitrogênio e palha em sistema semeadura direta na cultura do milho. Ciência Rural, v.36, p.460-467, 2006.

LARA CABEZAS, W.A.R.; ALVES, B.J.R.; CABALLERO, S.S.U.; SANTANA, D.G. Influência da cultura antecessora e da adubação nitrogenada na produtividade de milho em sistema plantio direto e solo preparado. Ciência Rural, v.34, p.1005-1013, 2004.

LARA CABEZAS, W.A.R.; ARRUDA, M.R.; CANTARELLA, H.; PAULETTI, V.; TRIVELIN, P.C.O.; BENDASSOLLI, J.A. Imobilização de nitrogênio da uréia e do sulfato de amônio aplicado em pré-semeadura ou cobertura na cultura de milho, no sistema plantio direto. Revista Brasileira de Ciência do Solo, v.29, p.215226, 2005.

MAI, M.E.M.; CERETTA, C.A.; BASSO, C.J.; SILVEIRA, M.J.; PAVINATO, A.; PAVINATO, P.S. Manejo da adubação nitrogenada na sucessão aveia-preta/milho no sistema plantio direto. Pesquisa Agropecuária Brasileira, v.38, p.125-131, 2003.

MALAVOLTA, E.; VITTI, G.C.; OLIVEIRA, S.A. Avaliação do estado nutricional das plantas: princípios e aplicações. 2.ed. Piracicaba: Potafos, 1997. 319p.

MARTINEZ, H.E.O.; CARVALHO, J.G.; SOUZA, R.B. Diagnose foliar. In: RIBEIRO, A.C.; GUIMARÃES, P.T.G.; ALVAREZ VENEGAS, V.H. (Ed.). Recomendação para o uso de corretivos e fertilizantes em Minas Gerais: 5aa aproximação. Viçosa: CFSEMG, 1999. p.143-168.

MENDONÇA, E.S.; OLIVEIRA, F.H.T. Fornecimento de nutrientes pela matéria orgânica do solo. In: SIMPÓSIO SOBRE
FERTILIDADE DO SOLO E NUTRIÇÃO DE PLANTAS NO SISTEMA PLANTIO DIRETO, 1., 2000, Ponta Grossa. Anais. Ponta Grossa: Associação dos Engenheiros Agrônomos dos Campos Gerais, 2000. p.70-81.

PAULETTI, V.; COSTA, L.C. Época de aplicação de nitrogênio no milho cultivado em sucessão à aveia-preta no sistema plantio direto. Ciência Rural, v.30, p.599-603, 2000.

PEREIRA, J.C.V.N.A.; MASCARENHAS, H.A.A.; MARTINS, A.L.M.; BRAGA, N.R.; SAWASAKI, E.; GALLO, P.B. Efeito da adubação nitrogenada em cobertura no cultivo contínuo do milho e do algodão e em rotação com soja. Revista de Agricultura, v.63, p.95-108, 1988.

PÖTTKER, D.; WIETHÖLTER, S. Épocas e métodos de aplicação de nitrogênio em milho cultivado no sistema plantio direto. Ciência Rural, v.34, p.1015-1020, 2004.

REDDY, G.B.; REDDY, R.K. Fate of nitrogen-15 ammonium nitrate apllied to corn. Soil Science Society of America Journal, v.57, p.111-115, 1993.

SÁ, J.C.M. Manejo da fertilidade do solo no sistema plantio direto. In: SIQUEIRA, J.O.; MOREIRA, F.M.S.; LOPES, A.S.; GUILHERME, L.R.G.; FAQUIN, V.; FURTINI NETO, A.E.; CARVALHO, J.G. (Ed.). Inter-relação fertilidade, biologia do solo e nutrição de plantas. Viçosa: SBCS; Lavras: UFLA/DCS, 1999. p.267-310.

SANGOI, L.; ALMEIDA, M.L. Doses e épocas de aplicação de nitrogênio para a cultura do milho num solo com alto teor de matéria orgânica. Pesquisa Agropecuária Brasileira, v.29, p.13-24, 1994.

SILVA, E.C.; MURAOKA, T.; BUZETTI, S.; TRIVELIN, P.C.O. Manejo de nitrogênio no milho em Latossolo Vermelho sob plantio direto com diferentes plantas de cobertura. Pesquisa Agropecuária Brasileira, v.41, p.477-486, 2006.

SILVA, P.S.L.; SILVA, P.I.B. Efeitos de épocas de aplicação de nitrogênio no rendimento de grãos de milho. Pesquisa Agropecuária Brasileira, v.37, p.1057-1064, 2002.

SOUSA, D.M.G.; LOBATO, E. Adubação com nitrogênio. In: SOUSA, D.M.G.; LOBATO, E. (Ed.). Cerrado: correção do solo e adubação. 2.ed. Brasília: Embrapa Cerrados, 2004. p.129-146.

Recebido em $1^{\circ}$ de agosto de 2007 e aprovado em 11 de dezembro de 2007 